\title{
Effectiveness of mannequin based 'NSSK' training in Auxiliary Nurse Midwives working in rural India.
}

\author{
Dr.S.D.Kotnis ${ }^{1}$ Dr.A.P.Kumavat ${ }^{2}$ Dr.S.P.Kulkarni ${ }^{3}$ Dr.Pramila Menon ${ }^{4}$ \\ ${ }^{1}$ Assistant Professor, Department of preventive and social medicine, Dr. Vaishampayan .Memorial Government \\ Medical College Solapur. \\ ${ }^{2}$ Professor, and head, dept of P.S.M;Dr. V.M.G.M.C. Solapur,state-Maharashtra, India. \\ ${ }^{3}$ M.O.DISTRICT Training cente., Solapur \\ ${ }^{4}$ Asso. Prof. Dept. of Genetics, Immunology, Biochemistry, MUHS, PUNE, India.
}

\begin{abstract}
Objectives: 1) To know change in knowledge level after NSSK Training in peripheral health workers. 2) To know the skills \& confidence development in handling cases of neonatal asphyxia in them.

Introduction- The ministry of health \& family welfare has launched the mannequin based, practically oriented NSSK (i.e., NAVJAAT SHISHU SURAKSHA KARYAKRAM,FOR MANAGING BIRTH ASPHYXIA AND OTHER COMMON MORBIDITIES OF NEWBORN, AT BIRTH ) training to all such health workers.

Time now has come to evaluate its effectiveness as an ongoing evaluation especially in the PHNs, who are the important link in the maternal \& newborn care with professional experts.

Materials and Methods- NSSK training for total 157 PHNs working in different Primary and community health centers in district Solapur (Maharashtra)has been conducted during October 2011 to January 2012 in different batches. This is observational study on the participants, before and after the training.

Results: The knowledge and confidence level was significantly improved $(P<0.001)$ after training. Participants expressed the novelty of abdominal delivery and realized importance of keeping baby dry and warm,timing \& method of suction, positioning. $(p<0.001)$ They expressed their willingness to practice the abdominal delivery, breast crawls, Kangaroo methods in fields. $98 \%$ were confident to use AMBU bag when required.

Conclusion: The mannequin based hand-on training is quite beneficial for effectively changing of knowledge and confidence to practice resuscitation measures in peripheral health workers. This will help us to achieve NRHM objectives of giving quality health services within our available resources and reducing Infant mortality(neonatal) rate.
\end{abstract}

Statistical Tests- Paired ' $t$ ' test.

Keywords: NSSK, mannequin, Performance evaluation test, PHNs. Abdominal delivery,

\section{Introduction}

Under the NRHM (RCH-II) programme, India has determined to reduce MMR, IMR with best possible training to peripheral health staff. ${ }^{1}$ Although childhood \& infant mortality in India has reduced substantially during the last decade, the rate of early neonatal mortality is still high. New born care often receives less than optimum attention, where they require healthy start of life. The Ministry of health, India points, [2] the need for resuscitation should always be anticipated. Thus, every birth attendant should be skilled in newborn resuscitation, (including anticipation, preparation, timely recognition and quick and correct action) and should have the necessary equipment and supplies - clean and functioning - to be able to respond quickly and correctly when needed.

WHO [3] points towards a survey of health care institutions in 16 developed and developing countries showed that there was often no basic equipment for resuscitating newborns, or that it was in poor condition and health personnel were not properly trained in newborn resuscitation.

In countries like India, most of the deliveries occur in villages by trained/untrained birth attendants or primary health centers or sub centers. Under the RCH-II national health programme essential and emergency obstetric and neonatal care has been given due importance ${ }^{1}$. And this will reduce the IMR \& MMR still further.55\% neonatal mortality is due to infections, preterm deliveries \& asphyxia.

Hence the important step in this is to train the peripheral health workers i.e. Medical officers, Health assistants and ANMs in technological sound conduction of deliveries with immediate routine care \& Neonatal resuscitation with bag \& mask ventilation.

The ministry of health \& family welfare 3 has launched the mannequin based, practically oriented NSSK training to all such health workers.

Time now has come to evaluate its effectiveness as an ongoing evaluation especially in the PHNs, who are the important link in the maternal \& newborn care with professional experts. Hence the current study is undertaken. 


\section{Materials and methods.}

NSSK training for ANMs and PHNs working in different Primary and community health centers in district Solapur (Maharashtra) has been conducted, on 157 Public Health Nurses during October 2011 to January 2012 in different batches. Each training session consisted of two full working days. The trainer and trainee ratio was maintained as 1:4 with a baby mannequin \& all the equipments for baby's respiratory resuscitation.(viz. clean and dry towels, mucus sucker, cord cutter, cord tie, cotton wools, baby cap, socks, radiant warmer, AMBU bag with accessories and oxygen cylinder. ) Every group was trained at the district training center, Solapur.

The workshop methodology included Lectures, Group discussions, Demonstrations, videos and individual practice with real equipments and mannequin with pre and post tests. All the participants were given Pretest 1 which included written questionnaire for evaluation of knowledge \& Pretest 2 which included evaluation of performance based on standard NSSK module prepared by ministry of Health \& FW, Govt. of India \& IAP. After training, posttests were conducted for the same. Evaluation of both, pre and post tests were done with the use of appropriate biostatistician tests to know effectiveness of the training.

After training and resuming duties, each participant was asked questions to know change in the practice according to the training by telephonic or personal contact

Statistical test applied-Paired t test.

III. Results.

Table1. Pre and post training evaluation of knowledge.

\begin{tabular}{|l|l|l|l|l|}
\hline & \multicolumn{2}{|l|}{$\begin{array}{l}\text { PRE TEST } \\
\text { (Satisfactory knowledge.) }\end{array}$} & $\begin{array}{l}\text { POST TEST } \\
\text { (Satisfactory knowledge.) }\end{array}$ \\
\hline & No. & Pretest $(\%)$ & No. & Post test (\%) \\
\hline \% of newborns requiring resuscitation & 41 & 26.11 & 148 & 94.27 \\
\hline Hand washing & 49 & 29 & 155 & 98.73 \\
\hline Warm chain for baby & 22 & 14.01 & 156 & 99.36 \\
\hline Use of mucus catheter & 130 & 82.8 & 157 & 100 \\
\hline Evaluation of every baby at zero minutes & 140 & 89.17 & 157 & 100 \\
\hline Equipments for baby needed at birth & 45 & 28.66 & 157 & 100 \\
\hline Ventilation of the baby with 'AMBU' bag & 0 & 76.43 & 155 & 100 \\
\hline Abdominal delivery & 0 & 0 & 157 & 100 \\
\hline Kangaroo care for tha baby & 90 & 57.32 & 155 & 98.73 \\
\hline
\end{tabular}

t- Test, $\mathrm{p}<0.01$

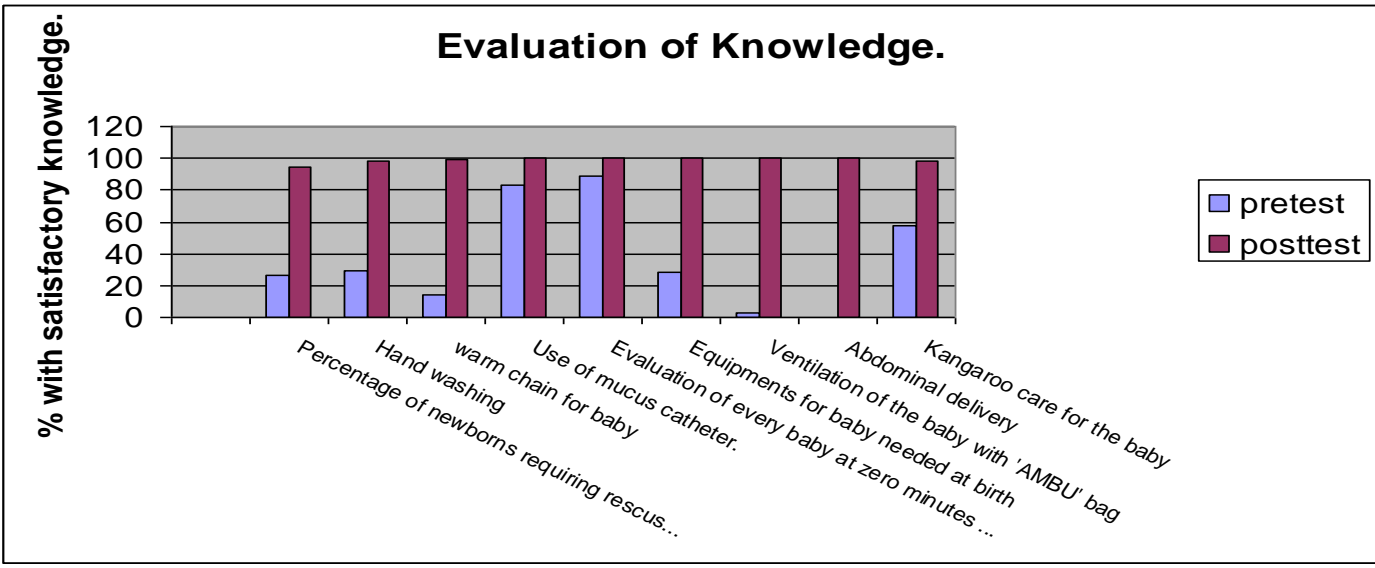

Figure1. pre and post training evaluation of knowledge

Table:-2.Performance Evaluation Test. (Practice)

\begin{tabular}{|l|l|l|l|l|}
\hline Practice of- & Pretest & \multicolumn{2}{l|}{ Post Test } \\
\hline & No & \% & No & \% \\
\hline Steps of hand washing & 15 & 9.55 & 152 & 96.82 \\
\hline Wearing Gloves & 9 & 5.73 & 148 & 94.27 \\
\hline Warm chain & 10 & 6.37 & 157 & 100 \\
\hline Keeping ready an assistant & 11 & 7 & 157 & 100 \\
\hline
\end{tabular}




\begin{tabular}{|l|l|l|l|l|}
\hline Keeping ready dry sheets, mucus catheter & 140 & 89.17 & 157 & 100 \\
\hline keeping ready 'AMBU' bag & 0 & 0 & 157 & 100 \\
\hline replacing baby's wet sheet & 14 & 9.55 & 155 & 98.73 \\
\hline Correct steps to help baby breath & 2 & 1.27 & 154 & 98.73 \\
\hline correct indication to use 'AMBU' bag & 8 & 5.1 & 156 & 99.36 \\
\hline Correctly operating the AMBU' bag & 4 & 2.55 & 150 & 95.54 \\
\hline Breast crawl & 9 & 5.73 & 150 & 95.54 \\
\hline Correct communication with the mother. & 3 & 1.91 & 152 & 96.82 \\
\hline
\end{tabular}

\section{$t$ - Test, $p<0.01$}

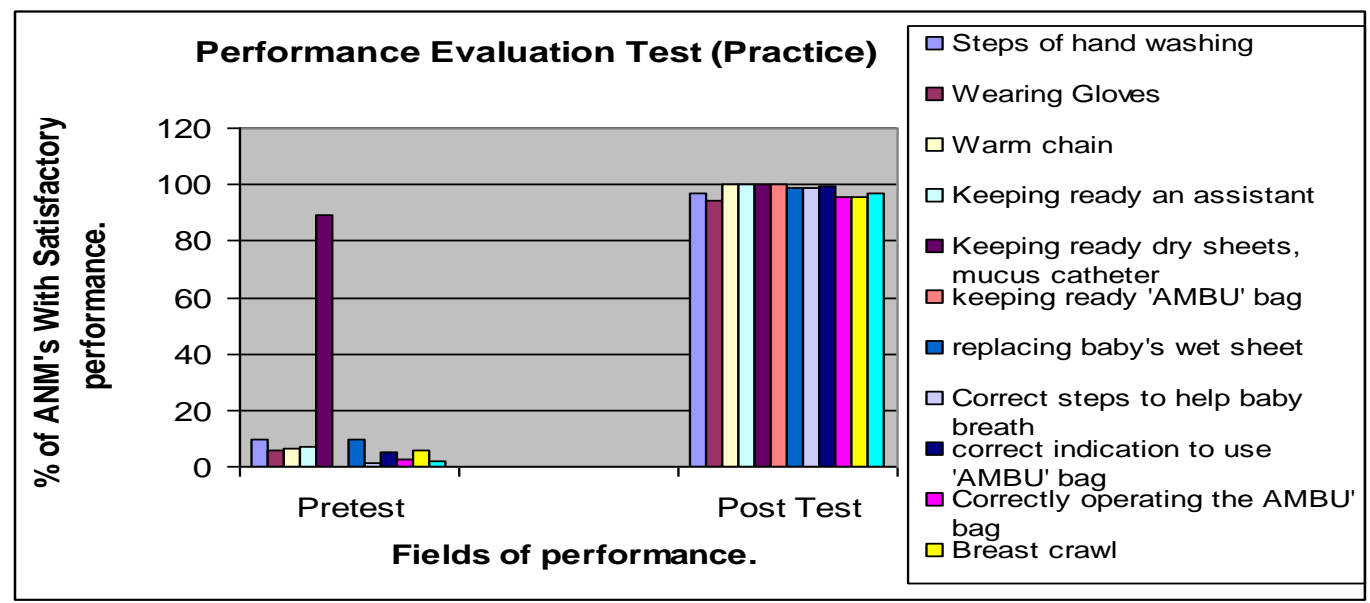

Figure 2. Performance evaluation test. (practice).

Table 3.Number of ANMs tried practicing the new Tequeniques in their field (community) after training.

\begin{tabular}{|l|l|l|}
\hline Techniques taught in the training & No of ANMs practiced it & \% \\
\hline Preparation before delivery & 121 & 77.07 \\
\hline Abdominal delivery & 65 & 41.4 \\
\hline Use of AMBU bag & 2 & 1.27 \\
\hline
\end{tabular}

\section{Discussion.}

We found mannequin based hands on training has given the required knowledge and giving confidence of practice in the peripheral health staff. $94 \%$ to $100 \%$ showed satisfactory improvement in the post test as compared with pretest, $(\mathrm{p}<0.01)$. Menan etal[4] also found the same training useful in interns. Rhodes [5]also appreciate mannequin based training for such skills, when clinical educators do not have time to teach clinical problems to students with appropriate learning opportunities.

Delivering the baby on mother's abdomen is totally new concept and many raised questions on its practicability. But $64(44 \%)$ gave us positive telephonic feedback. This needs to be evaluated in real practice. There is no such study that evaluated the practice. WHO [6] recommends delivering the baby onto the mother's abdomen.

Preparing for delivery; steps in hand washing were known prior to the training in $28 \%$ of paramedical workers, but knowledge, attitude, practice about their correct steps and importance was significantly improved. $94 \%$ to $99.36 \%$ showed satisfactory improvement in the post test as compared with pretest, $\mathrm{p}<0.01$. After the training.

The steps to help in respiration of the asphyxiated baby were adopted by the paramedical workers satisfactorily. This shows medical simulation helps to augment skills and confidence levels even in paramedicals. The same findings are seen in the study of Menan etal [4]and Brenner M etal. [7] Qualified doctors with good clinical reasoning skills and confidence would be expected to be competent in handling deliveries and neonatal resuscitation after having practiced mainly with manikins.[4] This is also true for nurses who are the first contacts with the patients and conduct deliveries at various maternity posts. Using manikins is a practical and safe approach to the acquisition and maintenance of task-oriented skills in medical specialties. "See one, do one, teach one" are the best approaches to the acquisition of health care related knowledge, skills and abilities. Simulation is a technique used "to replace or amplify real experiences with guided experiences that evoke or replicate substantial aspects of the real world in a fully interactive manner". Medical simulation helps to augment didactic instruction and hands-on experience in a safe environment 
without harming real patients. In NSSK training we have used manikins along with different imaginary case scenarios to impart knowledge and skills to the participants.

Trainings for birth attendants highlight that many simple interventions can prevent childhood mortality. $[8,9]$. Sanjiv Kumar[10] says, the techniques are known since long but still not reached large proportion of population. National Rural Health Mission (NRHM) from 2005 is a commendable effort to address many of the problems in health care delivery in rural India in capacity building through innovations in human resource management. Sanjiv Kumar[10] opines that, in India around 1.7 million children die every year and 730 every day, 3 every minute. Most of these deaths occur because many simple interventions which have been available for many decades still not reached large proportion of children. The killers of under fives in India include neonatal conditions, $35 \%$ of which include infections, preterm \& asphyxia. Training courses and training material will help health workers to carry out the task.

Basic resuscitation should also become part of the pre-service training of health care providers trained in midwifery. Gaining skills in newborn resuscitation cannot be left to the real-life situation and therefore training using manikins is recommended. It is very important that training in newborn resuscitation concentrates on the essential facts, skills and attitudes, and uses appropriate teaching methods and teaching aids (dolls/manikins). Training must focus on decision-making and Problem-solving skills in emergency situations, as well as on manual skills and on counseling skills for communicating with parents. It must emphasize the urgency of the situation and the need for coordinated activities by members of the health care team or, in case of a single health worker, on decision-making skills in dividing attention between the mother and the newborn. The appropriate level of competence should be achieved through continuing training.[8,9]As per the highlights given by WHO[9]the Millennium Development Goal for reducing child deaths cannot be met unless we do more to reduce neonatal deaths. Interim, feasible solutions are available that will save newborn lives in community settings whilst health systems are being strengthened, supporting the importance of training programme like 'NSSK'. Our study supports this view as $98 \%$ paramedical workers expressed that they would practice the skills taught during training while they are working in the community.

\section{Conclusions.}

The mannequin based hand-on training for peripheral health workers is quite beneficial for effectively changing of knowledge and confidence to practice resuscitation measures in peripheral health workers .This will help us to achieve NRHM (RCH) objectives of giving quality health services within our available resources and reducing Infant mortality(neonatal) rate.

The limitation of the study is we could not follow the health workers in actual field practice, and relay on their telephonic feedback.

\section{References.}

[1] K. Park. National Rural Health Mission,\& Reproductive and Child Health Programme.pages-406, 409, 410,411,413.Park's Textbook of Preventive and social medicine, $21^{\text {st }}$ edition.M/s Banarasidas Bhanot Publishers 1167, Premnagar , Jabalpur (M.P.)India.

[2] Ministry of Health and Family Welfare Government of India Navjaat shishu suraksha karyakram , Basic newborn care and Resuscitation program Facilitator's guide

[3] WHO-'safe motherhood: Basic newborn resuscitation: A practical guide. Maternal and Newborn Health/Safe Motherhood Unit. Division of Reproductive Health (Technical support.)

[4] Menon etal,Impact of manikin based training on interns. .IJPSR, vol.2(3),2011.121-123

[5] Rhodes $\mathrm{m}$, currant, use of the human patient simulator to teach clinical judgment skills in a baccalaureate nursing programme.CIN Computers, Informatics, Nursing 2005 Sept.0c;23(5):256-62.

[6] Ministry of Health and Family Welfare, Govt. of India. Navjaat Shishu Suraksha Karyakram: Basic newborn care and Resuscitation Programme; Training Manual.

[7] Bremner M, Aduddell K, Bennett D, VanGeest J. The use of human patient simulators: best practices with novice nursing students. Nurse educator.2006;31(4):170^4

[8] WHO Essential Newborn Care course .participant's workbook. www.who.int Last accessed 2011 Apr18.

[9] WHO.LancetneonatalSurvivalseries2005.Availablefromavailablefromhttp://www.who.int/child adolescent health/document s/lancet neonatal_survival/en,. Last accessed 2011 Apr18.

[10] Sanjiv Kumar. Editorial: Indians can do better at Improving child survival. IJCM July-Sept 2011/vol 36 (Issue 3 pp 171-173)

\section{Acknowledgement.}

I am very thankful to the District Health Officer, Solapur, for giving me the opportunity to work as a trainer (facilitator) for the NSSK training and permitting me for this publication.

I am also thankful to all the staff in the district training centre, Solapur for their kind co-operation, and the statistian, Mr. Mulje 